\title{
A PERCEPC̣ÃO SOCIAL À LUZ DE UMA CONCEPÇÃO PRAXIOLÓGICA DA INTENCIONALIDADE
}

\author{
The social perception in light of a praxiological conception of intentionality \\ La percepción social bajo la perspectiva de una concepción praxiológica de la intencionalidad
}

DANILO SARETTA VERISSIMO

\begin{abstract}
Resumo: Desenvolvemos uma discussão teórica da percepção social respaldada na compreensão das implicações das capacidades práxicas do sujeito perceptivo no estudo da intersubjetividade. Nossas análises são fundamentadas na matriz praxiológica de teorias enativistas e fenomenológicas, que servem de contraponto ao intelectualismo e ao internalismo que marcam as teorias correntes da percepção social. O conceito de atenção conjunta, concebido na década de 1970 no âmbito da psicologia do desenvolvimento infantil, e que se tornou um eixo articulador de programas de pesquisa voltados à percepção social, é utilizado como base para nossa investigação. Evidenciamos a possibilidade de fundar a percepção social no corpo e nas práticas do sujeito corpóreo de relação com o mundo mediadas pela interação e pela incorporação da atividade e da perspectiva do outro.
\end{abstract}

Palavras-chave: percepção; corpo; atenção conjunta, intersubjetividade, cognição social.

\begin{abstract}
We present a theoretical discussion of social perception based on understanding the implications of the praxic capacities of perceptive subjects in the study of inter-subjectivity. Our analyses are based on the praxiological matrix of enactive and phenomenological theories, which serve as a counterpoint to the intellectualism and internalism that mark current theories of social perception. The joint attention conception, conceived in the 1970s in the scope of child development psychology, and which links research programs focused on social perception, is used as the basis of our investigation. We show the possibility of grounding social perception in the body and the practices of the corporeal subject in relation to the world mediated by the interaction and the incorporation of activities and perspectives of another. Keywords: perception, body, joint attention, intersubjectivity, social cognition.

Resumen: Desarrollamos una discusión teórica de la percepción social respaldada en la comprensión de las implicaciones de las capacidades praxicas del sujeto perceptivo en el estudio de la intersubjetividad. Nuestros análisis son fundamentados en la matriz praxiológica de teorías enativistas y fenomenológicas, que sirven de contrapunto al intelectualismo y al internalismo que definen las teorías actuales de la percepción social. El concepto de atención conjunta, concebido en la década de 1970 en el ámbito de la psicología del desarrollo infantil, que se transformó en un eje articulador de programas de investigación dirigidos a la percepción social, es utilizado como base para nuestra investigación. Evidenciamos la posibilidad de fundamentar la percepción social en el cuerpo y en las prácticas del sujeto corpóreo de relacionarse con el mundo, mediadas por la interacción y por la incorporación de la actividad y de la perspectiva del otro.
\end{abstract}

Palabras clave: percepción, cuerpo, atención conjunta, intersubjetividad, cognición social.

Introdução

A percepção não se limita à ação de sujeitos individuais sobre objetos contextualizados apenas fisicamente. Ela se dá, principalmente, como atividade de sujeitos sociais, em um mundo socialmente contextualizado. Nosso propósito, neste trabalho, é evidenciar, teoricamente, como o exame da dimensão social da percepção reforça a tendência praxiológica de estudo da intencionalidade perceptiva, ou, na via reversa, como concepções praxiológicas da percepção enriquecem nossa compreensão da dimensão social da percepção. A referência que fazemos a teorias praxiológicas da intencionalidade denota um espaço conceitual embasado numa concepção corpórea da subjetividade, e que se pauta em um tipo de intencionalidade motora compatível com a posição de um sentido prático e vital da percepção. Esperamos desenvolver uma discussão da percepção social situada no contexto da compreensão das implicações das capacidades práxicas do sujeito perceptivo no estudo da intersubjetividade. Nossas análises são fundamentadas na matriz praxiológica de teorias enativistas e fenomenológicas, que servem de contraponto ao intelectualismo e ao internalismo que marcam as teorias correntes da percepção social. O conceito de atenção conjunta (joint attention), concebido na década de 1970 no âmbito da psicologia do desenvolvimento infantil, e que se tornou um eixo articulador de programas de pesquisa voltados à percepção social, será utilizado como base para nossas investigações.

$\mathrm{O}$ artigo começa com uma breve apresentação de problemas fundamentais envolvidos na dimensão social da percepção e da fecundidade da sua apreensão a partir da ideia de atenção, acompanhada da exposição de diretrizes descritivas e interpretativas acerca das pesquisas voltadas à atenção 
conjunta. Teremos ocasião de indicar, neste ponto, os pressupostos intelectualistas e mentalistas que sustentam a principal linha de trabalho em torno da atenção conjunta. Invocamos, na sequência, o que chamamos de princípios praxiológicos da intencionalidade perceptiva, direcionando-nos para abordagens enativistas e fenomenológicas da percepção social. De acordo com as contribuições destas abordagens, retornamos, em seguida, à ideia de atenção conjunta, buscando elaborar uma compreensão da atividade perceptiva social fundada nos processos de interação corpórea e de incorporação mútua.

\section{A dimensão social da percepção}

Nossa experiência é essencialmente intersubjetiva. Merleau-Ponty (1945) reporta-se à nossa relação com aspectos básicos da espacialidade, como a profundidade, a iluminação e a forma das coisas. Essa dimensão das nossas vivências constitui o que se poderia chamar, segundo o filósofo, de mundo físico, ou mundo natural. Mas o mundo físico, mesmo no sentido fenomenológico da expressão, que escapa às acepções das ciências naturais, não passa de um recorte abstrato da nossa experiência. E preciso compreender, como faz Merleau-Ponty (1945), que "quase toda a nossa vida" (p.31) se passa no mundo cultural. Estamos cercados por pontes, estradas, casas e utensílios, como óculos, cadeiras e colheres. "Cada um desses objetos carrega implicitamente a marca da ação humana à qual ele serve”, comenta Merleau-Ponty (1945, p.399). E estamos rodeados, principalmente, pela presença corpórea de outras pessoas. "O primeiro dos objetos culturais e aquele pelo qual eles todos existem, é o corpo de outrem enquanto portador de um comportamento”, complementa o filósofo (Merleau-Ponty, 1945, p.401). Orientando-nos pelo tema da percepção, é possível identificar, portanto, dois problemas básicos referentes à intersubjetividade: a questão da percepção do outro e a questão do vetor social que marca a nossa relação com as coisas.

Essa distinção aparece na literatura filosófica e científica contemporânea na forma dos problemas da cognição social, relativos a "como compreendemos os outros" (Gallagher, 2010, p.112), e da realização participativa de sentido (participatory sense-making), que diz respeito a "como compreendemos o mundo circundante com e mediante os outros" (Gallagher, 2010, p.112, grifos do autor). De acordo com Gallagher, trata-se de duas questões intimamente relacionadas, mas que, todavia, merecem ser diferenciadas. Pode-se afirmar que a diferença fundamental concerne ao objeto intencional em cada tipo de circunstância. Na realização participativa de sentido, o objeto central é o mundo e as coisas mundanas. O interesse recai, nesse caso, sobre a constituição de sentido no campo da interação intersubjetiva, ou, de modo mais geral, sobre a "co-constituição de um mundo significativo [meaningful world]" (Gallagher, 2010, p.113). No âmbito da cognição social, o objeto são os outros agentes, as pessoas, e o seu comportamento.
A dimensão social da percepção pode ser evidenciada quando a examinamos à luz dos problemas referentes à atenção. Constata-se, conforme as teorias fenomenológicas, que a aparição de um objeto exige o recuo do horizonte perceptivo. $\mathrm{Na}$ atividade perceptiva, operam-se, continuamente, seleções, de modo que algo possa aparecer. Não é possível ouvir ou ver tudo ao mesmo tempo. Identifica-se, portanto, na percepção, o que Weizsäcker (1939/1962) chama de restrição constitutiva, que coincide, em grande medida, com o tornar-se atento a alguma coisa. Esse acontecimento não é, todavia, um fenômeno solitário. Somos, frequentemente, cativados pelo outro, que se torna nosso objeto de atenção, ou por aquilo a que ele dedica atenção. A atenção dedicada a algo de modo partilhado pode se dar no plano de uma "co-atenção presencial" (Citton, 2014, p.127), caso em que duas ou mais pessoas, conscientes da presença de outrem, interagem com o mundo juntas, e no plano mais amplo de uma comunidade, ou mesmo no de uma sociedade de massas, em que as pessoas não compartilham, ao mesmo tempo, o mesmo lugar. $\mathrm{O}$ conceito de atenção conjunta, que analisaremos a seguir, diz respeito ao nível da co-atenção presencial, e nos endereça à intersecção das questões relativas à cognição social, ou, em termos mais gerais, à nossa percepção do outro enquanto ser sensível, e à percepção conjunta das coisas, quer dizer, à realização participativa de sentido. Por meio do exame dos problemas envolvidos na atenção conjunta, é possível desenvolver temas relativos a um importante aspecto da percepção: a sua dimensão corpórea, que demanda que as ideias de cognição e de sentido sejam discutidas com base em elementos da esfera sensório-motora, principalmente a ação e o movimento. ${ }^{1}$

\section{A atenção conjunta}

A atenção conjunta (joint attention) pode ser considerada uma plataforma conceitual que reúne pesquisas interdisciplinares voltadas ao estudo das origens da cognição humana, especialmente a linguagem e a compreensão social (Meltzoff, Kuhl, Movella \& Sejnowski, 2009). Nesse âmbito de pesquisa, concorda-se em definir a atenção conjunta como "um fenômeno profundamente social" (Seemann, 2011, p.195), com importante função na comunicação e na aquisição de conceitos.

$\mathrm{Na}$ psicologia do desenvolvimento, a atenção conjunta unifica, conceitualmente, uma série de habilidades sociais, por parte das crianças, no âmbito da percepção e da ação. Constata-se que a atenção conjunta começa a ocorrer em torno do nono e do décimo segundo mês de vida. Observa-se, nessa fase, que os bebês transpõem um regime diádico de

${ }^{1}$ É oportuno assinalar a distinção que se faz entre movimento e ação. De acordo com Rizzolatti e Sinigaglia (2008), a ação pode ser compreendida como o movimento envolvido por objetos significantes para nós, de modo que as atividades motoras em direção a eles possuem a conotação de movimentos voltados a uma meta. 
interação, ora com coisas, eventos ou situações, ora com outra pessoa. No esquema diádico, a criança, engajada atentamente na manipulação de algum objeto, não interage com o sujeito que por acaso esteja à sua volta. Ou, no caso de regozijar-se com a presença de alguém, não concede atenção aos objetos do ambiente. A partir dos nove meses de idade, passam a ser cada vez mais frequentes atividades em que a criança partilha com outrem um objeto de interesse, configurando, então, esquemas triádicos de interação, ou seja, ações que abarcam, além da criança, um parceiro e um objeto de percepção conjunta. Nessa nova estrutura de coordenação da percepção e da ação, a criança e o adulto conjugam sua atenção em relação a objetos e eventos (Tomasello, 1999; Moll \& Meltzoff, 2011). É justamente essa forma de interação, e os comportamentos a ela associados, que foi designada como atenção conjunta, desde os trabalhos pioneiros de Bruner (1983). ${ }^{2}$

As pesquisas realizadas em torno do assunto (Bruner, 1983; Tomasello, 1999; Moll \& Meltzoff, 2011; Bimbenet, 2011; Sheinkopf et al., 2016; Hurwitz \& Watson, 2016) revelam que os episódios primordiais de atenção conjunta e as habilidades correspondentes a ela emergem segundo um determinado padrão de desenvolvimento, que indica diferentes níveis de especificidade do triângulo referencial entre a criança, seu parceiro de atividades e os objetos circundantes. São mais comuns, inicialmente, situações em que, embora a interação por parte da criança com o adulto seja mediada por um objeto, a referência partilhada é incipiente, por exemplo, quando, atraída por uma coisa qualquer, a criança olha para o rosto do outro, buscando verificar se este se encontra envolvido na mesma cena e se se mostra ciente daquele mesmo objeto. Constata-se, nesses casos, a alternância do olhar da criança entre seu objeto de interesse e o seu parceiro social. Pouco a pouco, passam a se manifestar, de modo mais estável, atos em que o bebê acompanha o olhar ou as indicações gestuais do adulto, focalizando, então, sua ação perceptiva naquilo que prende a atenção do outro. Verifica-se, nessas circunstâncias, maior precisão em relação ao que olham e ao que se referem a criança e o seu par. Faz parte dessa categoria de realizações o aprendizado por imitação (imitative learning), caracterizado por situações em que a criança age com os objetos da forma como os adultos atuam sobre eles. A própria criança passa, mais tarde, a apontar e mostrar objetos e acontecimentos aos seus pares, dirigindo, então, a atenção e o comportamento destes.

Para Tomasello (1999), a emergência da atenção conjunta por volta dos nove a doze meses de idade configura um fenômeno coerente, ou seja, bem delineado, no desenvolvimento infantil. Mas seria preciso um passo a mais nos estudos, no sentido de se elaborar uma explanação, igualmente lógica, em torno do papel desenvolvimental da atenção conjunta. A hipótese teórica geral que congrega essa linha de pesquisas integra os compor-

${ }^{2}$ Neste trabalho, Bruner (1983) analisa suas pesquisas iniciais sobre a atenção conjunta à luz dos pressupostos teóricos que as fundamentam. tamentos triádicos ao problema da cognição social na infância. A hipótese específica é de que a atenção conjunta implica o início da compreensão, por parte da criança, do outro como agente intencional como ela mesma. Tomasello (1999) explica o sentido que dá à intencionalidade: "Agentes intencionais são seres animados que têm objetivos e que fazem escolhas ativas entre as formas comportamentais disponíveis para atingir aqueles objetivos, incluindo escolhas ativas sobre em que prestar atenção na busca desses objetivos” (p.68). A atenção seria, portanto, um tipo de percepção intencional, na medida em que, para Tomasello (1999), os indivíduos “(...) escolhem intencionalmente atentar [intentionally choose to attend] a certas coisas e não a outras" (p.68) em seu processo de busca por suas metas no ambiente. $\mathrm{O}$ autor dá o exemplo de um pintor e de um alpinista que, preparando-se para a realização de suas respectivas atividades, voltam seus olhares para uma determinada montanha. Embora vejam a mesma coisa, os dois atentam a aspectos distintos dela $^{3}$. Os comportamentos triádicos, especialmente aqueles em que a criança dá indícios de identificar com alguma precisão a "que" o adulto se dirige ou o "que" está fazendo, denotam, segundo Tomasello (1999), "uma clara compreensão da atenção do adulto” (p.69), embora ainda haja, por parte da criança, muito a conhecer acerca da relação entre a direção de um olhar e o foco de atenção.

Bruner (1983) também se reporta à possibilidade da referência conjunta, embora dirigida a um mesmo tópico atencional, envolver grande variação de exatidão. O exemplo aludido por ele é o de uma mãe, detentora de conhecimentos especializados em física, que alerta seu filho de quatro anos sobre o perigo de sofrer um choque elétrico ao explorar uma tomada. Este objeto não é visado da mesma maneira pelos dois, sobretudo em virtude da ideia de eletricidade que a mãe e a criança são capazes de atualizar nesta situação. Importa, todavia, que as partes envolvidas em uma "troca referencial" (Bruner, 1983, p.68) saibam que partilham alguma justaposição “em sua atenção focal” (Bruner, 1983, p.68).

O que convém enfatizar, portanto, é que, em situações de atenção conjunta, a criança não apenas compreende o outro como fonte de auto-movimento e de poder causal, mas como ser capaz de realizar escolhas comportamentais e perceptivas. Aliás, segundo Tomasello (1999), esta "distinção crítica” (p.74) estaria ausente, por exemplo, nas teorias de Piaget, que se limitaria a identificar, na

${ }^{3}$ Cabe, aqui, um breve apontamento sobre o sentido do termo intencionalidade. Tomasello (1999) atrela a intencionalidade atencional a uma operação de escolha e, com isso, reforça, unilateralmente, a dimensão voluntária do ato perceptivo. Na fenomenologia, âmbito teórico que será mobilizado mais adiante, designa-se pelo conceito de intencionalidade a referência básica de qualquer atitude humana a alguma coisa distinta do sujeito intencional, seja ela uma ideia, um julgamento, ou um objeto percebido ou imaginado. Nesse caso, a intencionalidade independe de uma vontade expressa de voltar-se para alguma coisa. Tomasello trabalha, portanto, com uma conotação mais prática e corrente da ideia de intenção, ou seja, como ato dirigido a um fim, a uma meta. Este sentido de intencionalidade tem relação com os embasamentos filosóficos do autor, mais próximos da filosofia da mente, e das suas implicações intelectualistas. 
criança, a capacidade de atribuir poderes causais ao outro. Para autores como Bruner (1983) e Tomasello (1999), está em questão, na atenção conjunta, a emergência da compreensão, por parte da criança, de outrem como percipiente, como ser dirigido a objetivos da mesma forma que ela mesma. Esta seria a base para que a criança se compreenda como participante em interação com o outro, com atenção focal justaposta, e para que a comunicação gestual evolua rumo à aquisição da linguagem.

\section{Princípios teóricos de interpretação da atenção conjunta}

Os princípios norteadores da posição adotada por precursores, como Bruner (1983) e Tomasello (1999), acerca dos problemas da ontogênese envolvidos na atenção conjunta advêm da filosofia da mente e dos seus desdobramentos nas ciências cognitivas, principalmente no que se convencionou chamar de teoria da mente. Admite-se, nesse contexto teórico, que o sujeito da cognição, em suas relações com outrem, ocupa-se predominantemente com a explicação do comportamento alheio, sobretudo com a previsão do curso ulterior das ações desse agente físico e das suas consequências no ambiente. Concorda-se, além disso, em atribuir a esse sistema comportamental, externo ao sujeito cognoscente, estados internos prováveis. De acordo com Petit (2004), a relação intersubjetiva, nesse enquadre filosófico, é sintetizada em um sujeito que, na interação com um outro, torna-se “"um atribuidor de propriedades mentais' a um 'objeto-alvo' do ambiente e do qual ele quer "predizer o comportamento' afim de antecipá-lo” (p.128) ${ }^{4}$. No que diz respeito aos processos internos do sujeito perceptivo que estariam envolvidos na interação com outrem, trata-se, para os pesquisadores, de investigar os mecanismos representacionais que possibilitariam a compreensão, constituída perceptivamente, da vida mental do outro. As hipóteses explicativas acerca desse processo passam, sem pretensão a uma listagem exaustiva, pela suposição de módulos mentais especializados na detecção da direção ocular de alguém, em mecanismos de compartilhamento da atenção, que seriam responsáveis pela formação de representações triádicas, além das teorias inferencial e da simulação, que tiveram grande aceitação nos programas de pesquisa voltados à atenção conjunta (Fuchs \& De Jaegher, 2009; Bimbenet, 2010, 2011; Seemann, 2011).

A teoria inferencial, também conhecida como teoria da teoria, e a teoria da simulação representam as principais interpretações da atenção conjunta atreladas à teoria da mente. Sua análise permite a identificação da permanência de concepções solipsistas no seio dos debates sobre o caráter social da vida mental.

Ambas se baseiam, no que se refere às pesquisas voltadas ao desenvolvimento infantil, em

${ }^{4}$ Por isso, Petit (2004), para referir-se à condição epistêmica do cognitivismo expressa nas análises da intersubjetividade, recorre à seguinte fórmula: “(...) cognitivismo = behaviorismo + mentalismo" (p.128). estudos que evidenciam a intensa sociabilidade das crianças desde fases bastante precoces da ontogênese. Das protoconversações em que os bebês se engajam junto com os seus cuidadores à capacidade do recém-nascido de imitar comportamentos dos adultos, como protusões da língua e abertura da boca, constata-se a tendência das crianças de se identificar com seus coespecíficos (Tomasello, 1999), ainda que com base em expedientes exclusivamente sensório-motores, destituídos de uma faculdade categorizadora. Meltzoff (1999), contudo, chega a assumir que os bebês, bem cedo, mediante os jogos de imitação recíproca na interação com outros agentes, adquirem informação sobre “(...) como o outro é ‘igual a mim' [like me]” (Meltzoff, 1999, p.256). Concorda-se em afirmar, de todo modo, a capacidade do bebê de se identificar em profundidade com seus coespecíficos, fato que constitui uma importante diferença na comparação comportamental entre os seres humanos e outros primatas.

Um segundo pressuposto das teorias inferencial e da simulação decorre das premissas básicas da teoria da mente: considera-se que, nas interações sociais, o sujeito perceptivo tem acesso direto ao comportamento do outro, mas não é capaz de experimentar diretamente suas crenças, desejos e intenções. Estes elementos são encarados como estados mentais que repousam, ocultos, sob o comportamento alheio. Seria necessário, portanto, construir, o tempo todo, teorias sobre as intenções dos outros. Este gênero de exercício inferencial teria origem bem cedo em nosso desenvolvimento. Meltzoff (1999) afirma: "é nossa teoria de que crianças têm teorias” (p.253, grifos do autor), sobretudo no que concerne à compreensão do comportamento intencional de outrem. Na teoria da simulação, defendida por Tomasello, o processo representacional de leitura das intenções estrangeiras baseia-se na ação mental de "colocar-se no lugar do outro". O pressuposto, nesse caso, é que o funcionamento psicológico das outras pessoas é compreendido com base no psiquismo do próprio percipiente, conhecido mais direta e intimamente por ele mesmo. Tomasello (1999) considera que, nesse sentido, as crianças, na medida em que adquirem a capacidade de se compreender como entes intencionais, no sentido de seres com propósitos referidos ao meio circundante, passam a aplicar esta compreensão ao comportamento de outrem. O outro pode, então, ser tratado como um agente psicológico, possuidor de interesses próprios e centro de uma atenção voltada a entidades que lhe são exteriores (Carpenter, Nagell \& Tomasello, 1998).

Consideramos as pesquisas em torno da atenção conjunta ricas em descrições e reflexões sobre a dimensão social da percepção. Desses estudos sobressai a inscrição da relação às coisas e ao mundo no contexto da sociabilidade, principalmente a emergência da consciência "de um ver em comum" (Bimbenet, 2011, p.309). Não se trata, simplesmente, do ponto de vista da criança, de olhar para aquilo que o outro olha, mas de tomar consciência de que o outro olha uma mesma coisa. O olhar conjunto constitui um ato, ao mesmo tempo, de referência e 
de comunicação, constatado ainda mais claramente quando a criança passa "a 'declarar' a coisa para o outro" (Bimbenet, 2011, p.309), apontando-a e mostrando-a para ele, quando se volta àquilo que interessa o outro, quando interroga sua atitude em relação ao objeto, expressivamente e, mais tarde, verbalmente.

Os estudos inaugurais da atenção conjunta denotam, por outro lado, um compromisso teórico com ideários mentalistas e intelectualistas. Seus pressupostos solipsistas comprometem a compreensão das bases psicológicas da relação com o outro e a conotação social de interação com o mundo (Petit, 2004). A abordagem da atenção conjunta realizada por autores como Tomasello e Meltzoff, denominada de perspectiva representacionalista (Fuchs \& De Jaegher, 2009), ou sócio-cognitiva (Bimbenet, 2010), acaba, com efeito, por enfatizar uma proto-compreensão, por parte da criança, de seus estados mentais e a ocorrência de processos reflexivos e de projeção desse conhecimento no outro. Desde que se considere a mente como um domínio interior apenas acessível ao próprio sujeito mental, a vida mental do outro não pode ser acessada senão indiretamente, segundo os indícios revelados pelo seu comportamento (Bimbenet, 2011). O pressuposto da teoria da mente é, além disso, de que o outro apenas pode ser reconhecido, desde o início, "como um outro eu mesmo" (Bimbenet, 2010, p.98). Do mentalismo decorre o intelectualismo. "Se o outro é constitutivamente um problema, é ao conhecimento, então, que ele se oferece em primeiro lugar", afirma Bimbenet (2011, p.349). Como o outro não se apresenta diretamente na relação social, seu entendimento exige processos de interrogação e de elaboração de um saber explicativo ou preditivo.

Em suma, tomado como parâmetro acerca das discussões contemporâneas sobre a percepção social, o conceito de atenção conjunta expressa a preocupação científica com a dimensão comum da nossa relação com o mundo. As interpretações preponderantes da atenção conjunta denotam, contudo, a primazia de um ideário mentalista capaz de comprometer a apreensão da conotação propriamente social da percepção.

\section{Interação corpórea e a incorporação mútua}

Concepções praxiológicas da percepção fazem o contraponto ao internalismo e ao intelectualismo das teorias tradicionais da percepção social. Mobilizamos, a seguir, aportes praxiológicos enativistas e fenomenológicos, conduzindo a sua apreciação para questões relativas à dimensão intersubjetiva da percepção, especialmente à ideia enativista de interação corpórea e à ideia fenomenológica de incorporação mútua. Iniciamos com breves apontamentos em torno da concepção de percepção como práxis.

Bimbenet (2015) esboça um retrato geral da convergência que subjaz a diversas manifestações teóricas em torno das possibilidades de um corpo ativo, e que o autor reúne sob a designação de "teo- rias praxiológicas da intencionalidade” (p.70). Bimbenet (2015) escreve:

O meio ambiente (Umwelt) em Uexküll; o mundo da vida (Lebenswelt) em Husserl, em suas modalidades corporais ou sócio-históricas; a disponibilidade (Zuhandenheit) e a preocupação (Besorgen) em Heidegger; a intencionalidade operante ou motora, em Merleau-Ponty, Gürwitsch ou mais tarde Dreyfus; o saber típico ou rotineiro do mundo social em Schütz; o knowing how que difere do knowing that em Ryle; as affordances de Gibson; o senso prático em Bourdieu; o saber-fazer encarnado (embodied coping) das teorias da enação etc.: além da sua evidente divergência, estas abordagens terão ao menos desenhado uma figura coerente da nossa relação com o mundo. Nisso pode-se falar de uma criação conceitual (p.65).

O elemento de confluência dessas abordagens repousa na atribuição de um caráter não apenas originário, mas, sobretudo, original à intencionalidade prática, ou ativa (Bimbenet, 2015). A descrição da nossa relação com o mundo pela ação e pelo movimento representa uma aproximação ao "fundamento arqueológico da nossa consciência" (Bimbenet, 2015, p.66). Antes de sermos sujeitos de pensamento e de estabelecermos uma relação teórica com o mundo e com outrem, somos seres vivos e ativos. O comportamento intelectualizado é, portanto, tardio e derivado em relação à nossa interação prática no mundo. Mas não se trata apenas de descrevê-la nos termos de uma anterioridade cronológica. A intencionalidade prática deveria ser pensada "a partir dela mesma" (Bimbenet, 2015 , p.66), e não com base em uma concepção instrumental da ação; eis a principal reivindicação das teorias praxiológicas da intencionalidade. A relação entre a ação e a percepção é, tradicionalmente, representada numa vinculação exterior, baseada na conjunção de uma representação de um objetivo a atingir, de uma trajetória a realizar, e na execução motora orientada por aquela representação perceptiva. A ação e o movimento deveriam, ao contrário, configurar uma atividade perceptiva, um tipo específico e irredutível de ser-no-mundo. Bimbenet (2015), ao circunscrever os fundamentos das teorias praxiológicas da intencionalidade, afirma: "Precisamos considerar a prática como um 'sentido' prático autóctone: uma compreensão, mas sem distância objetivante; uma familiaridade do corpo e do meio, mas que precede a distinção do conhecedor e do conhecido" (p.67). O autor completa: "Agir, mover-se, ocupar-se de algo, já é perceber, segundo uma modalidade específica” (p.67). A fenomenologia e o enativismo ocupam-se desse primado da prática na percepção, inclusive no que diz respeito à dimensão social da atividade perceptiva.

A ideia básica que permeia a concepção enativista, paradigma alternativo no interior da filosofia e das ciências cognitivistas, é de que a percepção é determinada pelo que fazemos. Noë (2004) afirma: "Percepção não é algo que acontece conos- 
co, ou em nós. É algo que fazemos” (p.01). A percepção não antecede, portanto, a ação, ela é antes uma ação perceptiva que estabelece e aprimora um saber sensório-motor. Em outro trabalho, Noë (2012) define a consciência perceptual (perceptual consciousness) como "um estilo especial de acesso ao mundo" (p.20, grifo do autor). A base desse acesso não deixa de referir-se a um polo de conhecimento e de entendimento. "Sem entendimento não há acesso e, portanto, não há percepção”, assevera o autor (Noë, 2012, p.20). Mas o entendimento no qual se fundamenta o acesso perceptivo às coisas e a outrem deve ser nomeado como "entendimento sensório-motor [sensorimotor understanding]" (Noë, 2012, p.20). Trata-se de uma forma de "conhecimento prático" (Noë, 2012, p.24) que, segundo o autor, independe do uso da linguagem. É esta forma de relação prática com as coisas, dependente das capacidades motrizes, que garante a presença perceptiva dos objetos. A constância perceptiva de aspectos das coisas, tais como o tamanho e a forma, bem como o volume dos objetos, seria assegurada pelo fato desses aspectos se configurarem, no âmbito da nossa relação prática com eles, como dimensões disponíveis à percepção mediante o movimento. De modo geral, observa-se nessas concepções um deslocamento, no plano teórico, de uma posição passiva, do organismo como receptor de informação e gerador de representações internas do mundo externo, para uma posição ativa de participação na geração de sentido.

No que se refere à intersubjetividade, coloca-se ênfase no processo de interação dos agentes perceptivos, e não em processos individuais de percepção do outro. Segundo Fuchs e De Jaegher (2009), a cognição social - ou, como preferimos, por nos afastar do linguajar intelectualista, a percepção social -, que se refere à percepção do outro e com o outro, emerge do processo dinâmico de interação com outrem, mais precisamente, da interação social corpórea. Os autores destacam o interesse, na abordagem enativista, pela "dinâmica circular com uma díade de agentes corpóreos [embodied agents]" (Fuchs \& De Jaegher, 2009, p.470). A emergência da interação pressupõe três fatores principais: que os agentes participem da situação de maneira a sustentá-la de algum modo, que o encontro influencie-os, e que os indivíduos "co-emerjam como interagentes com a interação” (De Jaegher \& Di Paolo, 2007, p.492). Da mesma forma, são componentes fundamentais do processo de interação fatores como a ressonância corpórea, a sintonia afetiva, a coordenação gestual, além da expressão vocal e facial. A interação possui uma dinâmica circular, calcada em processos de ressonância e de feedback, em que se dá a coordenação inconsciente de movimentos entre os agentes, como em situações de conversação, de jogo esportivo, de criação musical em grupo etc. Não se pressupõe, é claro, que a coordenação seja perfeita. Ela possui, antes, uma natureza dialética, elemento essencial para que, mais do que sincronização, atinja-se a autonomia do processo de interação. Isso quer dizer, conforme a síntese de Gallagher (2010), que a interação ultrapassa os participantes considerados individualmente. A dança a dois, por exem- plo, é algo dinâmico e que não pode ser criado individualmente.

A interação corpórea implica a coordenação e o compartilhamento de sentido. Em meio à coordenação interpessoal de movimentos emergem significados mutuamente compreensíveis, além de saliências perceptivas, quer dizer, objetos de atenção mútua (Fuchs \& De Jaegher, 2009; Gallagher, 2010). As "intenções-na-ação" (Fuchs \& De Jaegher, 2009, p.471) são visíveis. Atos como os de segurar, apontar, mover-se na direção de algo ou afastar-se de algo, acenar, olhar para alguma coisa, possuem um "sentido inerente” (Gallagher, 2010, p.115), são percebidos no "contexto de uma situação comum, sem a necessidade de se representar explicitamente o estado mental de outrem" (Fuchs \& De Jaegher, 2009, p.471). Na cena interativa, ações como aquelas solicitam, por parte do parceiro, ou dos parceiros, determinadas reações significativas. Se alguém aponta para um objeto, pode-se seguir o olhar ou a indicação deste sujeito. Todos os sujeitos, ou alguns dos envolvidos na cena, podem demonstrar aceitação da indicação e caminhar na direção do que foi mostrado, ou, ao contrário, podem se negar a dar atenção ao objeto, ou, senão, podem se afastar dele, por exemplo. Seja como for, constata-se a constituição de um "espaço comum” (Fuchs \& De Jaegher, 2009, p.472) em que a variação de movimentos, de atitudes e de expressões adquire sentido, que, por sua vez, é experimentado implícita ou explicitamente pelas pessoas envolvidas na cena. Aspectos inferenciais, como os privilegiados pela teoria da mente, não estão excluídos das situações sociais. Podemos transpor nosso olhar imaginariamente, perguntarmo-nos expressamente sobre o que olha e como olha nosso parceiro, pensar sobre as intenções possíveis do outro, todavia, à luz da condição corpórea de interação, essas estratégias não parecem refletir um nível primário de interação. A realização participativa de sentido (participatory sense-making) dependeria, primordialmente, da "coordenação da atividade intencional na interação”, afirmam De Jaegher e Di Paolo (2007, p.497), atividade "essencialmente corpórea [embodied] na ação” (De Jaegher \& Di Paolo, 2007, p.497).

A perspectiva enativista baseia-se, em alguma medida, na fenomenologia da percepção, da corporeidade e da intersubjetividade. Um dos elementos centrais das teorias fenomenológicas é a ênfase no estudo da intencionalidade corpórea como característica maior da estrutura da experiência perceptiva. Os fenomenólogos, de modo geral, descrevem o corpo como presença indelével e que, todavia, recua em relação ao centro do campo perceptivo em prol do aparecimento das coisas. Trata-se, em outros termos, de evidenciar o "auto-apagamento" (self-effacement) (Leder, 1990, p.25) do corpo como objeto de percepção, a despeito dele participar da manifestação de tudo que a nossa experiência compreende. Merleau-Ponty (1945), por exemplo, define o corpo como "o terceiro termo, sempre subentendido, da estrutura figura e fundo" (p.117). Todo objeto percebido, toda figura, destaca-se em relação a um fundo perceptivo, horizonte de espaço exterior que 
envolve o objeto e que participa, de um modo ou de outro, da sua configuração como objeto de percepção. Não há foco de percepção que não faça parte de uma configuração do tipo figura e fundo, ou tipo tema, contexto temático e margem, para usar os conceitos de outro fenomenólogo, Aron Gurwitsch (1957). O algo que aparece sempre aparece em meio a outros elementos com os quais mantém laços mais ou menos estreitos de sentido. Mas há uma estrutura de fundo fundamental, e que não faz parte do horizonte espacial: é justamente o corpo. Assim como o fundo perceptivo, que se mantém inarticulado em favor da clareza e distinção do objeto que se destaca como figura ou tema de percepção, nosso corpo recua à neutralidade como tema perceptivo, a despeito do seu caráter originário na relação intencional envolvida no aparecimento das coisas. O corpo é um fundo, um sistema de referência absoluto, no sentido de que tudo que aparece, aparece em relação a ele. E mesmo quando ele se torna objeto de percepção por parte do sujeito perceptivo, ele não se mostra completamente. O corpo como figura continua pressupondo uma larga margem de atividade corpórea que permanece de fundo.

Um dos aspectos centrais dessa descrição fenomenológica do corpo como sujeito da percepção refere-se à dinamicidade do repertório sensório-motor de relação com o mundo. Este se transforma incessantemente mediante a aquisição de novas habilidades e novos hábitos que, no mais das vezes, envolvem a utilização de instrumentos, ou mesmo de órgãos artificiais. Diz-se que as habilidades e instrumentos são incorporados. E, se o auto-apagamento é uma dimensão estrutural do corpo vivido, as extensões dos seus poderes sensório-motores, pela incorporação, devem abranger um grau significativo de ausência, ou de apagamento em proveito da atenção às coisas. Segundo Merleau-Ponty (1945), a pluma de um chapéu, o volume de um carro, a bengala de um cego, são acessórios corporais que, uma vez anexados, deixam de ser percebidos por eles mesmos. As extremidades da pluma, do carro e da bengala tornam-se zonas sensíveis, passam a "participar do caráter volumoso do corpo próprio" (Merleau-Ponty, 1945, p.168), assim como o aprendizado de um novo movimento de dança modifica o alcance da nossa visada espacial e dos nossos gestos. Estes instrumentos são integrados à nossa relação com o mundo, seu valor é intencional, referido ao mundo, e não auto-referido. $\mathrm{O}$ novo hábito, frisa ainda Merleau-Ponty, não é um novo conhecimento, nem um novo automatismo. Se é fato que, durante o período de aprendizado de um novo movimento ou da utilização de um novo instrumento, uma dose considerável de esforço intelectual e de repetição deve ser necessária, a aquisição do hábito depende de uma "consagração motora" (Merleau-Ponty, 1945, p.167). O que é, portanto, o hábito? "Trata-se de um saber que está nas mãos, que apenas se entrega ao esforço corporal e não se pode traduzir por uma designação objetiva”, afirma Merleau-Ponty (1945, p.168).

As exposições de Simone Weil (1988) acerca do hábito e da sua relação com os processos aten- cionais também são valiosas para a compreensão dessas questões. Embora a autora não integre a tradição fenomenológica, suas descrições são bastante próximas das ideias de autores como Merleau-Ponty. Weil (1988) afirma: "O hábito tem por efeito, em uma situação qualquer, de deixar passagem livre à ação; uma passagem pronta e livre entre percepção e ação" (p.383). Para a autora, é o hábito que nos dá "o poder de ter atenção" (Weil, 1988, p.386), na medida em que, no sujeito hábil, muitas vezes encarnado por ela na figura do trabalhador, a atenção é "atenção ao objeto" (Weil, 1988, p.386). O trabalhador, aquele que incorporara seu instrumento de trabalho, encontra-se "(...) em comunicação direta com o mundo exterior” (p.386). Já o aprendiz precisa, cuidadosamente, ter consciência dos seus movimentos. O hábito, anota a autora, nos torna "cidadãos do mundo" e "concidadãos dos homens" (Weil, 1988, p.387), na medida em que reitera nossas capacidades intencionais, no sentido fenomenológico de abertura às coisas e ao outro, de abertura ao mundo social.

No que diz respeito à relação com o outro e com o mundo mediante o outro, Leder (1990) caracteriza a sociabilidade justamente pela ideia de incorporação. O autor fala, no contexto social, de "incorporação mútua” (mutual incorporation) (p.94); segundo ele, de modo mais radical do que a incorporação de um instrumento, "nós suplementamos nossa corporalidade através do outro" (Leder, 1990 p.94). Podem constituir-se, desse modo, cenas intersubjetivas, nas quais vemos as coisas não apenas da nossa perspectiva, mas a partir, igualmente, da perspectiva de outrem. Seus gestos corpóreos, inclusive os linguísticos, abrem-nos para coisas que não havíamos percebido antes, sem que o foco da nossa atenção perceptiva seja o corpo de outrem ou o nosso próprio corpo, mas sim as coisas referidas gestualmente. Imagine, conforme o exemplo descrito por Leder, que você anda numa floresta junto com o seu parceiro, ou parceira. Um indica ao outro elementos variados da paisagem: a cor das plantas e das flores, um pássaro levantando voo, os sinais da mudança de estação. O ritmo dos passos de um ajusta-se ao do outro. Ambos desfrutam o passeio com o nítido sentimento de que o caminho seria percorrido diferentemente caso estivessem sozinhos. Vocês se distraem e conversam sobre outros assuntos, como política, cinema e, subitamente, adotam uma postura silenciosa, para apreciar o lugar. Nessa situação de encontro e de reciprocidade, o auto-apagamento do corpo em prol da percepção das coisas, processo também referido por Leder (1990) como "transcendência corpórea" (p.94), é perpetuado. $\mathrm{O}$ movimento de transcendência se dá, no entanto, de forma mútua. "Transcendemos juntos a um mundo comum, partilhando a floresta na qual caminhamos", afirma Leder (1990, p.94). O autor escreve, ainda: "Somos co-subjetividades, suplementando mais do que limitando as possibilidades de cada um" (Leder, 1990, p.94). Dá-se, de modo geral, uma expansão da perspectiva particular sobre o mundo a partir da perspectiva do outro. No intuito de clarificar a co-subjetividade, atrelan- 
do-a à ideia de incorporação, Leder cita um trecho da Fenomenologia da percepção, de Merleau-Ponty (1945), que convém reproduzir:

(...) é justamente meu corpo que percebe o corpo de outrem, e encontra nele como que um prolongamento miraculoso de suas próprias intenções, uma maneira familiar de tratar o mundo; doravante, como as partes do meu corpo formam juntas um sistema, o corpo de outrem e o meu são um único todo, o verso e o reverso de um único fenômeno, e a existência anônima da qual meu corpo é a cada momento o traço habita doravante estes dois corpos de uma só vez (p.406).

Mais adiante, na Fenomenologia da percepção, Merleau-Ponty (1945) fala da co-presença de dois sujeitos a uma paisagem. De acordo com seu exemplo, parecido com o de Leder (1990), se eu e Paulo nos mostramos, com os dedos, certos detalhes de determinada paisagem, o dedo de Paulo que indica um campanário não é um dedo-para-mim voltado a um campanário-para-mim. O próprio dedo de Paulo me mostra o campanário que este vê. Trata-se do mesmo campanário que vejo, embora o vejamos de perspectivas espaciais ligeiramente distintas, embora tenhamos diferentes histórias pregressas relativas a campanários. Além disso, se eu mostro algo a Paulo, não parece que desperto nele visões internas análogas às minhas: "parece-me, ao contrário, que meus gestos invadem o mundo de Paulo e guiam o seu olhar”, escreve Merleau-Ponty (1945, p.464).

Merleau-Ponty (1945) e Leder (1990) descrevem, portanto, um processo primário em que a percepção do corpo de outrem implica a transcendência intencional conjunta para o mundo. Pode-se dizer que, nos exemplos anteriores, os corpos dos integrantes das díades permanecem em "co-transparência” (Leder, 1990, p.95), quer dizer, fora do foco de atenção, "ecstaticamente [ecstatically] envolvidos com um mundo compartilhado" (Leder, 1990, p.95) ${ }^{5}$. Este é um elemento basilar da intercorporeidade, tal como tematizada pelos fenomenólogos.

Leder (1990) acrescenta, contudo, que o suplemento do nosso ponto de vista pela perspectiva alheia depende sempre do reconhecimento pré-reflexivo, ou prático, de uma distância entre perspectivas. "Mutualidade é impossível na ausência de distância”, afirma o autor (Leder, 1990, p.95). De acordo com esta lógica, podemos distinguir na particularização corpórea a asseguração de uma distância fundamental, de maneira que distância e mutualidade podem articular-se desde os primórdios da ontogênese. Antes de desenvolver uma imagem do seu próprio corpo e de si mesmo, o bebê é capaz de imitar os gestos dos adultos. Nota-se, nisso, não apenas o primado da mutualidade, mas, do mesmo modo, do distanciamento que possibilita a troca

${ }^{5} \mathrm{Na}$ fenomenologia, a menção ao acontecimento ecstático refere-se à abertura intencional do sujeito, ao seu direcionamento incondicional ao mundo. de olhares e que aparece como pré-condição para a consciência de si. O olhar face a face pressupõe uma não coincidência espacial, a qual, ainda que não seja reconhecida expressamente, como no caso do bebê, condiciona a experiência da mutualidade. A emergência da consciência de si, neste contexto, pode ser interpretada como um reconhecimento da distância.

Destacamos, portanto, em meio às contribuições do enativismo e da fenomenologia, as ideias de interação corpórea e de incorporação mútua. Admitindo-se a dinâmica entre os agentes corpóreos e o entrecruzamento de perspectivas intencionais, podemos vislumbrar a elaboração de novas linhas de interrogação da atenção conjunta.

\section{Ação partilhada}

Questões próprias à atenção conjunta podem ser pensadas a partir das concepções praxiológicas, enativistas e fenomenológicas, da percepção social. Da ressonância corpórea à cooperação na relação com o mundo, passando pela percepção, mediante interação, do sentido intencional do comportamento de outrem, buscaremos conceber, no âmbito do primado da prática, os contornos do processo de incorporação da agência de outrem.

O que se convencionou denominar, na psicologia do desenvolvimento, de "intersubjetividade primária” (Trevarthen, 1977, conforme citado por Bimbenet, 2010, p.101), e que se refere às formas de comunicação pré-verbais da criança, adequa-se bem ao que vimos acerca da interação corpórea entre agentes percipientes. O bebê capta muitas atitudes e expressões do adulto imediatamente. Levando-se em conta o egocentrismo sem sujeito da primeira infância, temos basicamente, na interação entre o bebê e o adulto, processos de ressonância emocional, de afinação mimética, de feedback mútuo. A criança e o adulto são "contemporâneos um do outro” (Bimbenet, 2010, p.101), sem que haja necessidade de transpassar a distância que separa os dois corpos. Esta distância, existente de fato, e que possibilita a troca de olhares, não é a distância entre um "eu", sujeito que se conhece, e um "ele", ente a ser conhecido a partir do si mesmo do sujeito percipiente. Nela se dá a ligação entre "um 'eu' [moi] e um 'tu' emocionalmente ressonantes, afinados mimeticamente”, comenta Bimbenet (2010, p.101). Esta condição opõe-se à intelectualização das relações conforme a abordagem cognitiva, e revela o caráter afetivo da relação entre a criança e o outro, além de não conceder "nenhuma precedência ao eu sobre outrem" (Bimbenet, 2010, p.101).

Os primeiros fenômenos de atenção conjunta, característicos de uma "intersubjetividade secundária” (Trevarthen, 1977, conforme citado por Bimbenet, 2010, p.101), marcam, sem rupturas extremas, a passagem da relação face-a-face à integração dos objetos na relação com outrem, da interação emocional e corpórea com o adulto à percepção do sentido intencional dos seus comportamentos, captados, igualmente, de modo interativo e coordenado. 
Nessa transição, a incorporação mútua, à qual se refere Leder (1990), adquire um telos propriamente intencional e conjunto. De formas variadas, e com graus diversos de intimidade, a criança e seus parceiros passam a atuar reciprocamente no mundo, alcançando, muitas vezes, grande harmonia cooperativa na relação com as coisas. Parece necessário verificar, com Bimbenet (2010), que aquilo que se conjuga, nesse caso, não são duas consciências que antes estariam separadas, como se pressupõe nas explanações teóricas advindas da perspectiva sócio-cognitiva, mas a atenção, corporalmente situada, a um mesmo acontecimento ou objeto. Convém notar, primeiramente, que esta última formulação é, prioritariamente, descritiva, enquanto a ideia da conjugação de atividades mentais possui uma conotação explicativa, além de recuperar teses mentalistas. Se considerarmos, ademais, que são as relações iniciais da criança com o adulto que se passam sob o signo da comunhão, o que ocorre, na medida do desenvolvimento das interações triádicas, pode ser entendido como uma separação incipiente de perspectivas. Começa a ser elaborada, aqui, por parte de Bimbenet (2010), uma tese a partir de elementos descritivos. Bimbenet (2010) afirma: "Na realidade, a atenção conjunta separa mais do que conjuga" (p.105). O autor faz a seguinte observação:

(...) a atenção conjunta, a partir dos nove meses, não poderia consistir na conjunção de duas consciências originalmente separadas. Os termos junção, conjunção, união ou reunião, todo este léxico leva a uma interpretação espontânea do fenômeno que não é necessariamente a melhor. (...) Seria preciso entender como um jogo de palavras pleno de sentido a expressão "atenção partilhada", a partilha significando cisão tanto quanto reunião. Os episódios de interação conjunta reúnem de fato dois indivíduos em torno de um fazer comum, mas justamente dois "indivíduos", convocados a parear dois pontos de vista ao menos espacialmente incompatíveis e, portanto, concorrentes, sobre a mesma coisa (Bimbenet, 2010, p.105).

As palavras de Bimbenet (2010) evidenciam a importância, no processo ontogenético, do descentramento infantil e da correlativa mudança em seus vínculos primitivos com o outro. Pode-se compreender melhor o que Leder (1990) diz acerca da integração entre suplementação intercorpórea de pontos de vista e o reconhecimento da distância que marca o perspectivismo. Nos primeiros eventos de atenção conjunta, é a multiplicidade perspectiva que se anuncia, de um modo ainda rudimentar. Tem início o processo de assunção progressiva da alteridade do outro, expressa na disposição deste como agente e observador. Assume-se, ou incorpora-se, portanto, os elementos de um distanciamento progressivo entre si e o outro. Outrem será reconhecido, cada vez mais, como ente "capaz de”, ou seja, como centro de atividade em direção a um mundo que não se esgota na minha visada ativa sobre ele.
Convém assinalar que as formulações de Tomasello (1999) destacam essa dimensão práxica da atenÇão conjunta. A despeito da partilha com outrem se dar, na sua interpretação, mediante simulação analógica, o que é partilhado é justamente, segundo as palavras de Bimbenet (2011), "uma intenção de fazer" (p. 312). Fato é que as coisas podem, desse modo, adquirir seu caráter transcendente, ou seja, seu aspecto de objetos que nos fazem face, não se reduzindo à nossa perspectiva sobre elas.

Este processo de triangulação referencial, envolvendo o eu, outrem e as coisas, se desenvolve com base em um jogo de reflexos especulares que dificilmente poderia ser tematizado apenas em termos intelectualistas. O distanciamento perspectivista, que possibilita graus crescentes de intelectualização, ou seja, de reconhecimento objetivo de outrem e do mundo, depende da identificação corpórea com o outro. Esta, por sua vez, é enriquecida pela constatação da distância em relação ao outro. Em sua análise acerca do gesto de indicação, Trân Duc Thao (1973) aborda a relação entre distância e reciprocidade, dinâmica que pode, inclusive, ser replicada de forma solitária pelo sujeito. Para Thao, pode-se falar de relação intencional do sujeito ao objeto, de uma "consciência originária do objeto" (p.18), a partir da "forma objetiva da indicação" (p.18). O movimento de indicação, observado na criança em situação de atenção conjunta, é, em sua forma originária, um guiamento à distância. Quando a estrutura do gesto de indicação é estabelecida, o sujeito é capaz de aplicá-la a si, indicando objetos para si próprio. É o que ocorre quando a criança se depara com uma cena interessante e, mesmo que não haja ninguém junto dela, aponta o dedo indicador para o objeto ou acontecimento em questão. "O movimento de indicação a si mesmo", pondera Thao (1973), "deriva naturalmente daquele de indicação a outrem” (p.19). Nesse caso, é necessário que o sujeito tome distância em relação a si mesmo, como quando realizamos um "diálogo interior" e dirigimo-nos a nós mesmos na segunda pessoa: "manifestamente, coloco-me na posição de um outro, que é precisamente eu mesmo", afirma Thao (1973, p.19). Isso é possível em função da relação de reciprocidade que mantemos com outrem. "No movimento do trabalho coletivo", completa Thao (1973), "os trabalhadores se indicam uns aos outros o objeto de seus esforços comuns" (p.19). Cada um dá e recebe indicações, cada um é guia e guiado. Cada um se percebe, reciprocamente, nessa dupla função. Isso não seria possível sem o reconhecimento do outro como alguém semelhante a si mesmo. Essa reciprocidade permite que, sozinho, o sujeito tome para si o ponto de vista dos outros, e indique a si próprio as coisas.

Fica claro, ao mesmo tempo, que a reciprocidade e a identificação, que ocorrem na interação social corpórea, não cessam de existir na assunção da distância, ao contrário, são pressupostas neste último processo. De um lado, o reconhecimento da alteridade do outro e do caráter transcendente das coisas que nos fazem face podem dar ensejo a visadas cada vez mais carregadas de intelectualiza- 
ção, como quando tentamos entender o que o outro sente, ou quando imaginamos a fisionomia da parte oculta de um objeto a partir da perspectiva ocupada por outrem, ou, ainda, ao concebermos um objeto geometricamente, como visto por todos os lados ao mesmo tempo. Por outro lado, este reconhecimento é permeado pela dimensão práxica envolvida na ressonância corpórea, na assunção dos gestos corporais dos outros, como a indicação e a fala, e na ocupação conjunta em torno dos objetos. Thao (1973) comenta: "O gesto de indicação, como guiamento à distância, é um chamado ao trabalho sobre o objeto indicado" (p.21-22, grifos do autor). Não passamos, portanto, da ação ao conhecimento, de uma atividade pragmática de ordem sensório-motora à representação das coisas. A atividade corpórea, envolta desde o início numa atmosfera social, abre-se cada vez mais a um senso do real, ou seja, a um ambiente de coisas que não pertencem apenas à minha visada e à minha esfera de ação, mas a uma visão comunitária e a uma ação partilhada. O erro a se evitar, na compreensão deste processo, é o de se conceber uma ruptura entre a atividade perceptiva do início da vida e a atmosfera partilhada que se alcança mais tarde. A atividade corpórea do início é essencialmente social, e, por sua vez, a sociabilidade que somos capazes de desenvolver, cada vez mais suscetível a acolher a ideia de um real independente de mim, é original e initerruptamente corpórea e ativa ${ }^{6}$.

\section{Considerações finais}

Desenvolvemos, neste trabalho, análises e reflexões em torno da dimensão social da percepção com base em duas matrizes praxiológicas de estudo da intencionalidade perceptiva: teorias enativistas e fenomenológicas. O disparador das nossas discussões foram posições de pesquisa consolidadas em torno do fenômeno de atenção conjunta. As teorias da atenção conjunta nos aproximam dos problemas referentes à percepção do outro e à percepção com ou a partir do outro, ou seja, à compreensão conjunta do mundo circundante. As interpretações de cunho mentalista e intelectualista da atenção conjunta serviram de motivo para que explorássemos contribuições enativistas e fenomenológicas, que, calcadas em princípios praxiológicos da intencionalidade perceptiva, propiciam o exame da intersubjetividade e da percepção social a partir de princípios práticos e corpóreos de interação e de incorporação mútua.

A implicação mais evidente das abordagens enativa e fenomenológica para o estudo da inter-

\footnotetext{
${ }^{6}$ Bimbenet (2015) escreve: "O realismo se premeditaria, contra toda expectativa, na afetividade, na identificação com o outro, na imitação, na simulação, em suma, em todas essas imaginações que compõem a paisagem literalmente 'extravagante' de uma sociabilidade humana. Seria necessário este ver plural, partilhado, disseminado, seria necessário este 'positivo' superabundante dos vínculos humanos para que fosse possível uma crença realista. É como se o universal se premeditasse na partilha da experiência e no calor das primeiras identificações, no que Merleau-Ponty chamou um dia, para aí assentar a possibilidade de um mundo intersubjetivo, 'os pensamentos bárbaros da primeira idade"” (p.181).
}

subjetividade e, mais especificamente, da atenção conjunta, refere-se à restrição da intelectualização da intersubjetividade a comportamentos em relação a outrem mais tardios no plano da ontogênese. Reforça-se, com isso, a possibilidade de fundar a comunicação simbólica no corpo e nas práticas do sujeito corpóreo de vinculação com o mundo mediadas pela interação e pela incorporação da atividade e da perspectiva do outro. No que diz respeito especificamente ao conceito de atenção conjunta, reconhece-se, à luz dos dispositivos teóricos da interação e da incorporação mútua, uma transição referida não à conjugação de consciências separadas, mas ao surgimento de uma distância entre perspectivas, com suas consequências intencionais. A atenção a um objeto comum a partir de perspectivas distintas advém da dialética própria aos processos de interação corpórea e de incorporação mútua, em que não existe apenas imitação, mas a realização de novos sentidos mediante o acoplamento de ações.

\section{Referências}

Bimbenet, E. (2004). Nature et humanité: le problème anthropologique dans l'ouvre de Merleau-Ponty. Paris: Vrin.

Bimbenet, E. (2010). Pour une approche phénoménologique de l'attention conjointe. Alter: Révue de Phénoménologie, 18, 93-110.

Bimbenet, É. (2011). L'animal que je ne suis plus. Paris: Gallimard.

Bimbenet, E. (2015). L'invention du réalisme. Paris: Les Éditions du Cerf.

Bruner, J. (1983). Child's talk: learning to use language. New York, London: Norton \& Company.

Carpenter, M., Nagell, K. \& Tomasello, M. (1998). Social cognition, joint attention and communicative competence from 9 to 15 months of age. Monographs of the Society for Research in Child Development, 63(4), 1-142.

Citton, Y. (2014). Pour une écologie de l'attention. Paris: Éditions du Seuil.

De Jaegher, H. \& Di Paolo, E. (2007). Participatory sense-making: an enactive approach to social cognition. Phenomenology and the Cognitive Sciences, 6, 485-507.

Fuchs, T. \& e De Jaegher, H. (2009). Enactive intersubjectivity: participatory sense-making and mutual incorporation. Phenomenology and the Cognitive Sciences, 8, 465-486.

Gallagher, S. (2010). Joint attention, joint action, and participatory sense making. Alter: Révue de Phénoménologie, 18, 111-123.

Gurwitsch, A. (1957). Théorie du champ de la conscience. Bruges: Desclée de Brouwer. 
Hurwitz, S. \& Watson, L. (2016). Joint attention revisited: finding strengths among children with autism. $\mathrm{Au}$ tism, 20(5), 538-550.

Leder, D. (1990). The absent body. Chicago / Londres: The University of Chicago Press.

Meltzoff, A. (1999). Origins of theory of mind, cognition and communication. Journal of Communication Disorders, 32, 251-269.

Meltzoff, A., Kuhl, P., Movella, J. \& Sejnowski, T. (2009). Foundations for a new science of learning. Science, 325, 284-288.

Merleau-Ponty, M. (1945). Phénoménologie de la perception. Paris: Gallimard.

Moll, H. \& Meltzoff, A. (2011). Joint attention as the fundamental basis of understanding perspectives. In A. Seemann (Org.), Joint Attention: new developments is psychology, philosophy of mind, and social neuroscience (pp.393-413). Massachusetts: MIT Press.

Noë, A. (2004). Action in perception. Cambridge/London: The MIT Press.

Noë, A. (2012). Varieties of presence. Cambridge/London: Harvard University Press.

Petit, J-L. (2004). Empathie et intersubjectivité. In A. Berthoz \& G. Jorland (Orgs.), L'empathie (pp.123147). Paris: Odile Jacob.

Rizzolatti, G. \& Sinigaglia, C. (2008). Les neurons miroirs (M. Raiola, Trad.). Paris: Odile Jacob.

Seemann, A. (2011). Joint attention: toward a relational account. In A. Seemann (Org.), Joint Attention: new developments in psychology, philosophy of mind, and social neuroscience (pp.183-202). Massachusetts: MIT Press.

Sheinkopf, B., Sheinkopf, S., Tenenbaum, E., Tronick, E., Shankaran, S., Bauer, C.,...Lester, B. (2016). Infant's early vision attention and social engagement as developmental precursors of joint attention. Developmental Psychology, 52(11), 1721-1731.

Thao, T. D. (1973). Recherches sur l'origine du langage et de la conscience. Paris: Editions Sociales.

Tomasello, M. (1999). The cultural origins of human cognition. Cambridge: MIT Press.

Weil, S. (1988). Oeuvres completes, Vol. I: Premiers écrits philosophiques. Paris: Gallimard.

Weizsäcker, V. (1962). El circulo de la forma: teoría de la unidad de percepción y movimento. Madrid: Ediciones Morata. (Originalmente publicado em 1939).
Danilo Saretta Verissimo, sob regime de co-tutela, Doutorou-se em Psicologia pela Universidade de São Paulo e em Filosofia pela Université Jean Moulin - Lyon III, França. Possui formação de Psicólogo, Bacharelado e Mestrado em Psicologia pela USP. Ocupa o cargo de Professor Assistente Doutor (MS3.2; RDIDP) na UNESP, lotado no Departamento de Psicologia Social e Educacional da Faculdade de Ciências e Letras de Assis. Leciona história e epistemologia da psicologia. É credenciado junto ao Programa de Pós-Graduação em Psicologia da mesma Faculdade, integrando a linha de pesquisa Epistemologia e Psicologia: a Relação SujeitoObjeto. Faz parte do Grupo de Pesquisa (CNPq) "Epistemologia e Psicologia: processos e contextos de desenvolvimento humano". Atuou como psicólogo do Departamento de Neurologia, Psiquiatria e Psicologia Médica do Hospital das Clínicas da Faculdade de Medicina de Ribeirão Preto-USP. Áreas e temas de concentração de suas pesquisas e publicações: filosofia e psicologia da percepção; fenomenologia; filosofia e história da psicologia; percepção, corpo e movimento; percepção, atenção e sociedade contemporânea; Merleau-Ponty; epistemologia do desenvolvimento humano; psicologia da saúde. Email: danilo.verissimo@gmail.com

Recebido em 02.11.2017 Primeira Decisão Editorial 20.06.2018

Aceito em 28.07.2018 